\title{
Recent patent applications in drug screening
}

\begin{tabular}{|c|c|c|c|c|c|}
\hline Patent number & Description & Assignee & Inventor & $\begin{array}{l}\text { Priority } \\
\text { application } \\
\text { date }\end{array}$ & $\begin{array}{c}\text { Publication } \\
\text { date }\end{array}$ \\
\hline WO 2009089189 & $\begin{array}{l}\text { A microfluidic cell culture system including a medium } \\
\text { inlet reservoir, cell culture areas, perfusion barrier, cell } \\
\text { inlet/media outlet reservoir, large fluidic opening, fluidic } \\
\text { multiplexor and fluidic reservoirs; useful in the drug } \\
\text { screening industry. }\end{array}$ & $\begin{array}{l}\text { Cellasic } \\
\text { (San Leandro, CA, USA) }\end{array}$ & Hung PJ, Lee PJ & $1 / 3 / 2008$ & $7 / 16 / 2009$ \\
\hline US 7560530 & $\begin{array}{l}\text { An isolated and purified complex of human ST2 } \\
\text { and human interleukin-1 receptor accessory protein } \\
\text { (IL-1RACP); useful in drug screening and diagnosis of } \\
\text { immune disorder, e.g. allergy. }\end{array}$ & $\begin{array}{l}\text { Schering } \\
\text { (Kenilworth, NJ, USA) }\end{array}$ & $\begin{array}{l}\text { Chackerian AA, } \\
\text { Kastelein RA }\end{array}$ & $7 / 20 / 2006$ & $7 / 14 / 2009$ \\
\hline CN 101463343 & $\begin{array}{l}\text { A new cell model having a human interleukin (IL)- } 1 \beta \text { gene } \\
\text { promoter; useful for screening an anti-inflammatory drug. }\end{array}$ & $\begin{array}{l}\text { Tongji University } \\
\text { (Shanghai, China) }\end{array}$ & $\begin{array}{l}\text { Fei J, Jing } \mathrm{H}, \mathrm{Li} \mathrm{L} \text {, } \\
\text { Wang Z }\end{array}$ & $12 / 30 / 2008$ & $6 / 24 / 2009$ \\
\hline JP 2009124968 & $\begin{array}{l}\text { A cell electrophysiology measuring device used in drug } \\
\text { screening, comprising a dispensing unit, which fills the } \\
\text { cavity of a sensor tip with a measurement liquid. }\end{array}$ & $\begin{array}{l}\text { Matsushita Denki Sangyo } \\
\text { (Osaka, Japan) }\end{array}$ & $\begin{array}{l}\text { Hiraoka S, Nakatani M, } \\
\text { Oshima A, Ushio K }\end{array}$ & $11 / 21 / 2007$ & $6 / 11 / 2009$ \\
\hline WO 2009057528 & $\begin{array}{l}\text { A kit for producing a molecular probe for positron emis- } \\
\text { sion tomography drug screening, containing a furan- } \\
\text { containing compound, a formamide compound, an } \\
\text { isoquinoline compound and their salt. }\end{array}$ & $\begin{array}{l}\text { Hamamatsu Photonics } \\
\text { (Shizuoka, Japan), } \\
\text { RIKEN (Saitama, Japan) }\end{array}$ & $\begin{array}{l}\text { Doi H, Suzuki M, } \\
\text { Tsukuda H }\end{array}$ & $10 / 31 / 2007$ & $5 / 7 / 2009$ \\
\hline WO 2009051599 & $\begin{array}{l}\text { A method for diagnosing Alzheimer's disease comprising } \\
\text { exposing the test cell sample to a labeled amyloid beta } \\
(A \beta) \text { and determining an intracellular level of the labeled } \\
A \beta \text { in the test cell sample. }\end{array}$ & $\begin{array}{l}\text { MP Biomedicals } \\
\text { (Santa Ana, CA, USA) }\end{array}$ & Fiala M & $10 / 19 / 2007$ & $4 / 23 / 2009$ \\
\hline WO 2009024869 & $\begin{array}{l}\text { A biological device comprising a substrate including a } \\
\text { hydrophobic surface adapted for oriented association or } \\
\text { attachment and/or oriented spreading of molecules having } \\
\text { hydrophobic part(s); for use in biomembrane research and } \\
\text { drug screening. }\end{array}$ & $\begin{array}{l}\text { Czolkos I, Erkan Y, } \\
\text { Jesorka A, Orwar O }\end{array}$ & $\begin{array}{l}\text { Czolkos I, Erkan Y, } \\
\text { Jesorka A, Orwar O }\end{array}$ & 3/26/2007 & $2 / 26 / 2009$ \\
\hline CN 101343633 & $\begin{array}{l}\text { A method of preparing a HER2 stable expression cell } \\
\text { system for screening drugs for preventing and/or treating } \\
\text { mammary cancer comprising inserting the HER2 encod- } \\
\text { ing gene into the multiple cloning site of a eukaryon } \\
\text { expression carrier. }\end{array}$ & $\begin{array}{l}\text { Beijing University } \\
\text { (Beijing) }\end{array}$ & Lan R, Zhang $\mathrm{C}$, Zhang $\mathrm{H}$ & $9 / 5 / 2008$ & $1 / 14 / 2009$ \\
\hline
\end{tabular}

Source: Thomson Scientific Search Service. The status of each application is slightly different from country to country. For further details, contact Thomson Scientific, 1800 Diagonal Road, Suite 250, Alexandria, Virginia 22314, USA. Tel: 1 (800) 337-9368 (http://www.thomson.com/scientific). 